\title{
Improving Student's Vocabulary Through Story Innovation Strategy (A Case Study at SMAN 5 Makassar)
}

\author{
Dian Rahmawati Arief ${ }^{*}$ \\ ${ }^{1}$ Department of English Language Studies, Universitas Hasanuddin, Makassar, Indonesia \\ *dianrarief@gmail.com
}

\begin{abstract}
Vocabulary is one of the components that strengthen students' language skills. Hence, learners might find it challenging to understand when people communicate using English in daily life without mastery of vocabulary. It becomes the foundation for students to learn more about English. It is necessary to improve English vocabulary among the students as their second language. In addition, teachers have an essential role in the English learning process. In the English learning process, teachers should act as educators and innovators and also they must know the method suitable for the students' vocabulary improvement. This study aims to determine the influence of Story Innovation Strategy teaching methods on student learning outcomes and determine students' interest in the methods used. The research method used is quantitative and qualitative. The object of this research is the first-grade students in SMA Negeri 5 Makassar. Data were collected by Pre-test, Treatment, Post-test, and Questionnaire. The data is analyzed by calculating the score and then classifying the score from the highest to the lowest level. These results indicate that Story Innovation Strategy can improve students' vocabulary skills. The post-test result shows that $2217(73,79 \%)$ has been given after treatment total overall score higher score while pre-test result is 1567 (57,56\%) delivered before the total score low score and interest students toward SIS methods was high. This can be seen from the results of the questionnaire that has been given.
\end{abstract}

Key words: Student, improving, teaching method, vocabulary.

\section{Introduction}

Language plays an essential role in our social life. It is used for daily activities, education, research, and science as a communication tool, especially in written and spoken language. The use of language can make communication between one person to another, and It is essential to keep up with and learn what is being presented daily. Without the existence of language, it can cause misunderstanding among the people. Every person usually masters two languages to communicate with each other in their daily life. It can be a national or international language. People use English as their second language in their country, which is almost used throughout the world. That is why people seriously learned about this language. As an international language, English is essential to understand. It is widely used in every aspect such as science, business, economics, culture, etc. English has become the main subject in every level from elementary school to university to create competent Indonesian students who are ready to compete 
internationally in various aspects. There are four essential language skills that students should master well: reading, listening, writing, and speaking. These skills are influenced by several language components such as vocabulary, grammar, and socio-culture [1]. Vocabulary, in particular, is the crucial thing that learners must know at first. It is considered an essential element in improving the mastery of these four basic skills in English.

Vocabulary is one of the components that strengthen students' language skills. Hence, learners might find it challenging to understand when people communicate using English in daily life without mastery of vocabulary. That is why vocabulary becomes the foundation for students to learn more about English. However, vocabulary is one of the most comprehensive and challenging aspects of English for Indonesian students to master thoroughly. If it is not resolved immediately, students will not become competitive globally. That is why it is necessary to improve English vocabulary among the students as their second language. In addition, teachers have an essential role in the English learning process. In the English learning process, teachers should act as educators and innovators and also they must know the method suitable for the students' vocabulary improvement.

Therefore, Story Innovation Strategy can be the alternative strategy to help students to improve their vocabulary. Story innovation is an instructional strategy to innovate a book or text. It was introduced by Martin and Brogan. This strategy makes a learner able to create innovative sentences through word substitution. It can be a powerful instructional strategy that can improve' learners vocabulary. As a result, the finished product is a new text accessible for students to read and understand. They are already familiar with every word in the original text with the new vocabulary used to create the innovation. In this strategy, the students have to focus on vocabulary. They must also thoroughly understand the context and patterns of the text. It is also considered an ideal strategy for the teacher to apply. Because this strategy supports the students to learn in a non-threatening, low-anxiety, and highly supportive learning environment, Story Innovation Strategy can also increase the students' reading skill and writing skills. In the writer's opinion, reading and writing activity has a powerful impact on improving vocabulary because learners must know about the meaning before they read or write the text.

In this paper, the writer conducts Story Innovation Strategy in improving students' vocabulary. The students are given the text, and the writer guides them to innovate or re-create it. But, before they innovate the text, they must thoroughly understand the context and the words in the text.

When students are aware of these strategies, they become more motivated to learn and actively participate in the learning process. This research gives a contribution to the development of knowledge about teaching methods in vocabulary improvement. It can also enrich knowledge on applying Story Innovation Strategy suitable for students' level and needs. Practically, this research is expected to contribute to the students, the English teachers, and other researchers. For the students, this research is expected to become an ideal and easy method in improving students' vocabulary. For English teachers, this strategy is expected to give information about various techniques suitable for the students to improve students' vocabulary. This strategy can also be used by the teacher in the vocabulary teaching process. The last is for other researchers. The writer hopes this study can inspire and reference future research to increase the quality of teaching and learning English as a foreign language. In addition, this study is expected to provide contributions related to the issue, especially in linguistic majors.

\section{Theoretical Reviews}

\section{Vocabulary}

Vocabulary is the knowledge that studies a word, part of a word that gives clues to the meaning of whole words. Vocabulary is a core component of language proficiency and provides much of the basis for how well learner speaks, listen, read and write[1]. Vocabulary as 1)all the words that a person knows or uses;2) all the words in a particular language;3) the words that people use when they are talking about a particular subject; 4) a list of words with their meanings. Then, vocabulary is a collection of words in a particular language that an individual knows and has a meaning [1]. It means that a language consists of several words that form a meaningful language.

Vocabulary as knowledge of words and word meaning in both oral and written language and effective and receptive forms [2]. More specifically, they use vocabulary to refer to "the kind of word that students must know to read increasingly demanding text with comprehension." Nunan says that vocabulary is more than lists of target language words. Vocabulary is part of the language system.

In addition, vocabulary means an extensive collection of items. Learning vocabulary is essential because it improves someone's knowledge of words [2]. The students should acquire several vocabularies about the story innovation strategy to understand better reading an English text. Vocabulary as knowledge; a word implies a definition and indicates how that word fits into the world. Vocabulary knowledge is not something that can ever be fully mastered; it expands and deepens throughout a lifetime [3].Vocabulary is one of the components of language. vocabulary also define as a list or set of words for a particular list or set of the word that individual speakers of language might use [4]. Vocabulary can be defined as the words that the teachers teach in a foreign language.

There are several types of vocabulary. Based on four skills in language learning, Vocabulary is divided into four groups [2]. The four groups of vocabulary are as follows: 
- Listening vocabulary; all the words they can recognize when listening to speech. It influences the learners' in-class lectures, class discussion, etc

- Reading vocabulary is all the words they can recognize when reading. They are the words which one responds to the meaning and understanding in writing

- Writing vocabulary is the words they can employ in writing. It determines how accurately they can express ideas through writing

- Speaking vocabulary is all the words they can use in speech. They are the words that come out of the tongue in one conversation. Speaking language affects how well people understand and react.

Concerning kinds of vocabulary, Nation states that there are four categories of vocabulary, they are:

- High-frequency words. These words are almost $80 \%$ of the running words in the text.

- Academic words. Typically, these words make up about $9 \%$ of the running words in the text.

- Technical words. These words make up about $5 \%$ of the running words in the text. It is used by people working in a specialized field.

- Low-frequency words. These are the words of moderate frequency that do not manage to get into the highfrequency list. They make up over $5 \%$ of the terms in an academic text [2].

It is essential to master vocabulary. It can help the learners to enjoy the clauses. Ones who master enough vocabulary will face fewer difficulties than those who have less vocabulary [4]. Concerning the role of vocabulary in the teaching-learning process. Scrivener stated there are five roles of vocabulary, they are:

- Vocabulary is essential and needs to be dealt with systematically its own right

- We need to distinguish between vocabularies for productive use receptive recognition

- The learner will find it challenging to finish the work if they have first met some new vocabularies

- Learners need to deal not only with single-word lexical items but also with longer, multi-word items.

- Learners are trained to use English-English dictionaries. It provides learners with a vital tool for self-study [5].

In the language learning process, vocabulary is one of the essential aspects for the learners. If the learners have less vocabulary, they can not understand English. The learners will be unable to access information and knowledge. In addition, the ones who have less vocabulary cannot understand the ideas that they have read or listened to.

To improve vocabulary, students have to know where the source of vocabulary comes from, so the students will be easier to learn English. There are some sources vocabulary studies are [6]:

- Word list Word list is an economical way of memorizing and understanding vocabulary for learning, and it does not matter if they are put together randomly. The students can learn the language wherever they are because it is easy to bring.

- Vocabulary book it is also integrated into skill work, typically in a pre-task or post-task vocabulary focus. There is many vocabulary and task in vocabulary book, which can be an exercise for the students.

- The teacher The teacher is a potentially fruitful source of vocabulary input not only in terms of accidental learning but also as a means of introducing vocabulary through interaction between the students and the teacher

- Learner Each learner can contribute to the shared clause lexicon through thought activities as brainstorming. Learners can improve their vocabulary from other learners by discussing and sharing their knowledge.

- Short text Short text for vocabulary-building purposes, whether spoken or written, has enormous advantages over learning words from a list.

- In improving students' vocabulary, the teacher and the learner greatly influence students' ability, especially in the teaching-learning process. The teacher must make the appropriate strategies to make the learners feel enjoy in learning vocabulary. Thus, they will be easier and faster in memorizing new vocabulary that they have read or listened to .

In addition, there are four points to improve the vocabulary mastery that students need to know [7], they are as follows:

- Word Meaning The first thing to realize about the vocabulary items is that they frequently have more than one meaning. For example, the word "book" obviously refers to something we read from - a set of printed pages fastened together inside a cover. However, in the dictionary, these words are listed into eight more meanings: a noun, two as a verb, and three where "book + preposition" make phrasal verb. Therefore, when we find a word and try to describe its meaning, we should also look at the content on which it is based.

- Word Use The meaning of words can change depending on their use them. Word meaning is frequently stretched through the use of metaphors and idioms. For example, the word "hiss" describes the noise that snakes make. But, it can be extended to describe the way people talk to each other. This is symbolic use. Another example is the 
word "snake." It can be defined as the treacherous person in a combination of words, "snake in the pass" it is a fixed phrase that has become an idiom like continues other phrases such as "raining cats and dogs", putting the cat among the pigeons". Straight from the horse's mouth, etc .

- Word Formation The shape and the grammatical value of words can also be changed. Students need to know facts about word formation and how to twist words to fit different grammatical contexts. Students also need to know the suffixes and prefixes words and how words are spelled and sound. Indeed, the way words are stressed is vital if the students can understand and use words in speech. Part of learning a word is learning it is written and spoken form. Moreover, word formation means knowing how words are written and spoken and understanding how they can change their form. Thus, the verb "run" has the participle "running" can be used as an adjective and "run"can also be a noun.

- Word Grammar Just as words change according to their grammatical meaning, certain words can trigger the use of a particular grammatical pattern [8].

There are many areas of grammatical sense, so the use of specific grammatical patterns. There are many areas of grammatical behavior that students need to know [9]. What is the distinction between countable and uncountable nouns, and how do they behave? How do verbs behave in such grammatical patterns? What are phrasal verbs, and how do they behave? How adjective ordered? What position can be adverbs be used in? Knowing a word means far more than just understanding (one of) its meaning. Somehow, our teaching must help students understand what this knowledge implies both in general and for certain words in particular. By being aware of this knowledge, students will be more receptive to the contextual behavior of words when they first see them in text, etc. They will be able to manipulate both meaning and forms [10]

\section{Story Innovation Strategy}

Every learner and teacher has a strategy to improve and develop their vocabulary in the vocabulary learning process. The teacher plays an essential role in introducing new words to the learner. Learning vocabulary gives a critical contribution to learning a language, which the teacher must consider to be careful in selecting the vocabulary that will be taught [11]. They must decide which words should be given since there are many kinds of words that belong to different vocabulary and what strategies that suitable for the learners. One of the strategies that teachers and learners can apply is the story innovation strategy. This strategy is an instructional strategy introduced by Martin and Brogan . Martin and Brogan discussed a procedure to innovate a sentence through the structure of a sentence to create new word substitutions. Story innovation is "a written expression motivated and sustained by the secure patterns of the favorite verse" [12]. Besides that, the concept of this strategy did not attract enough attention from teachers, and it begins forgotten in recent decades. Story innovation is a strategy that makes the learner enjoy writing and reading in a scaffolded format. This strategy results in a new text that is easy for the learner to read and understand because they are familiar with the patterns in the original story and with the new vocabulary used to create the innovation.

Besides that, the story innovation strategy involves a tight interface between word knowledge and oral reading fluency, and it allows the learner at all levels to feel successful. Even though this strategy is a part of instructional strategies, it is not yet common in many primary classrooms. Therefore, Griffith and Yuan have identified the procedure for teachers to follow [13]:

- Determining how a story might be innovated

- Familiarizing students with the sentence and episode patterns within the story to be innovated

- Developing student's oral vocabulary around a topic that interests them and that will later be used in the story innovation

- In addition, for story innovations to be successful, students must engage in deep processing of the target vocabulary employed in the book and the words they want to use to change the text. They must truly understand the context of particular words used and make changing words meaningful and enjoyable.

According to Griffith and Ruan, the first step of a story innovation strategy is to negotiate with the learners what words or parts will be changed. First, the learners can be innovated by changing the characters, action verbs, story setting, and dialogue or sounds. The learners also can arrange other elements if the students are "advanced readers" and more experienced in story innovation. This strategy needs deep processing of the specific vocabularies used in the text and the new vocabularies selected to replace the original ones. In addition, the learner and the teacher can also use the story map to explore the structure or the part of the story. The purpose of the story map is to inforced learners' understanding about the setting and characters of the story because those are the elements to be changed when the learners' create a new story.

From the explanation above, we can conclude that story innovation strategy can increase two aspects, reading and writing skills. According to Nuttal, reading is an effective way to improve vocabulary mastery [14]. Students will have many chances to find new words by reading and become familiar with them. It helps students study vocabulary, 
and they will recognize the words automatically and can also improve their reading skills. Therefore, students will be more confident and more understanding in reading English text [15].

Day and Bamford divided several benefits of reading, as follows:

- Increasing reading ability. This is unsurprising since that is the stated goal of extensive reading.

- Increasing interest and motivation. Reading is one of the skills that is enjoyable. Students read books that they choose based on their level. This pleasure can impact the success of learning English

- To improve vocabulary, students need to meet words or vocabulary in a context many times to acquire it. Reading is an excellent way to achieve this.

- Improving listening, speaking, and spelling abilities. If listening and speaking are unsuccessful in the class, extensive reading can support these skills. It increases exposure to English vocabulary and discourse.

- Facilitating acquisition. Most current theories of second language acquisition recognize the roles of language input and intake. Reading provides these necessities [16].

After that, this activity can improve learners' writing skills through summarizing and note-taking. Those activities are an excellent technique for writing activities [17]. The story map in the process of story innovation strategy makes the learners concerned about the details of the story. Therefore, they must understand the meaning of the words before they write the story map. In addition, Griffith and Ruan stated this strategy created non-threatening, low anxiety, and highly supportive learning environment [18] Story innovation strategy also provides opportunities for repeated reading practice that factor helps the students become successful readers.

\section{Methodology}

The methods of this research are quantitative, quantitative method of this research is experimental research method. Basically, experimental research aims to examine the law of cause and effect (Davis, 2004:3). This research design with one group pre-test and post-test design. Pretest is the test which given to the students before the treatment, and post-test was given to the students after the treatment to find out the student achievement. The research formula is designed as follows:

$\mathrm{O}_{1}$ - - - - X - - - $\mathrm{O}_{2}$

Where :

$\mathrm{O}_{1}$ : pre-test; $\mathrm{X}$ : treatment; $\mathrm{O}_{2}$ : post-test

The population in this research is all first grade students' at SMA Negeri 5 Makassar. The numbers of population is 300 students from first grade. In this study, the sampling use random sampling techniques from the number of population. The total of samples are 30 students. Simple random sampling is the most widely-used probability sampling method.

\section{Findings and Discussion}

The findings of the research are based on the results of the data analysis. The vocabulary test consists of pre-test and post-test. The pre-test was given to find out the prior knowledge of students in vocabulary before presenting the treatments. At the same time, the post-test was assigned to determine the improvement of the students' vocabulary after utilizing the whole treatments using Story Innovation Strategy. The scores that the writer gives to the students are taken from written tests. The test consists of 40 items vocabulary test. The writer concluded that students' levels of vocabulary mastery were low. It can be proven that 1 students achieved 80-100 score that classified into Excellent, 2 students achieved got 70-79 score that classified into Good, 9 students achieved got 60-69 scores that classified into Fair, 5 students achieved 50-59 scores that classified into Poor, and there are 13 students earned 0-49 scores that classified into very poor. Based on the students' answers in the pre-test above, the writer concluded that the student's vocabulary mastery before they were given the treatment was low. Based on the following reasons why the students' vocabulary mastery was low. First of all, the students find it challenging to understand and master English. This makes the students have difficulties answering the content of the test. After that, self-motivation among the students in improving vocabulary is low. Last, the students find it challenging to find an appropriate method to enhance their vocabulary.

It can be concluded that some students have a lot of improvement from pre-test and post-test that the writer has given to them. In this case, the students' vocabulary mastery also has a lot of progress. It can be proven that 13 students are classified into Excellent, 7 students classified into Good, 6 students classified into Fair, 3 students classified into Poor, and 1 student classified into Very Poor.

Based on the explanation above, the writer concludes that Story Innovation Strategy makes a lot of improvement toward students' vocabulary mastery. The conclusion is relevant with the theory of Griffith and Ruan stated that this strategy created non-threatening, low anxiety, and highly supportive learning environment in improving students' vocabulary, and according to Nuttal (2005), reading is an effective way to enhance vocabulary mastery because 
students will have many chances to find new words. This strategy builds students' sense to read and write the story. Through reading and writing, they are able to master vocabulary

Table 1. The Mean Score and Standard Deviation of The Students' Pre-Test and Post-Test

\begin{tabular}{lll}
\hline & Pre-test & Post test \\
\hline Mean score & 52,5 & 74,25 \\
Standar Deviation & 9,41196353 & 12,6391565 \\
\hline
\end{tabular}

\section{Conclusion}

Based on this research, Story Innovation Strategy is one of the great methods to improve students' vocabulary. The result can be seen through the scores of pre-test and post-test. The mean scores of the post-test with 73,9 is higher than pre-test with 52,2. By visiting this improvement, it can be concluded that students are interested and enjoy learning vocabulary using this strategy. Furthermore, the percentage of the students' scores in vocabulary mastery using Story Innovation Strategy shows enhancement with $73,79 \%$ and $57,76 \%$ of the pre-test. The conclusion is relevant to the theory of Griffith and Ruan. Story Innovation Strategy is ideal for teachers and students to use with struggling readers or learning English as a second language ( ESL). This strategy created a non-threatening, low-anxiety, and highly supportive learning environment.

The students' perceptions of using Story Innovation Strategy in improving students' vocabulary are mostly positive. They enjoyed learning vocabulary using this strategy because Story Innovation Strategy (SIS) is easy and fun to apply. Moreover, they get advantages from this strategy. They can improve their reading and writing skill. Through innovating the story, they can gain vocabulary by reading and writing.

\section{References}

[1] J. Harmer, "Review: Methodology in Language Teaching: an Anthology of Current Practice," ELT Journal, vol. 58, no. 1, 2004, doi: 10.1093/elt/58.1.80.

[2] K. K. Frankel, B. L. C. Becker, M. W. Rowe, and P. D. Pearson, "From 'What is Reading?' to What is Literacy?," Journal of Education, vol. 196, no. 3, 2016, doi: 10.1177/002205741619600303.

[3] A. Budiman, "Behaviorism and Foreign Language Teaching Methodology," ENGLISH FRANCA: Academic Journal of English Language and Education, vol. 1, no. 2, 2017, doi: 10.29240/ef .v1i2.171.

[4] "Using Self-Portrait Series and Video in Teaching Writing to Students with Low and High Motivation," English Education Journal, vol. 8, no. 1, 2018, doi: 10.15294/eej .v8i1.22130.

[5] S. Li, "The effects of phonics instruction on L2 phonological decoding and vocabulary learning," 2019.

[6] D. Lismayanti, “Developing Students’ Vocabulary Using Monolingual Dictionary”.vol. 1 no. 1 june 2012.

[7] S. S. Heha, D. L. Nurafifah, and M. R. Pradita, "Improving Vocabulary Using Initial Letters Gameat The Fourth Grade Of Sdn Harapan 01 Cimahi," PROJECT (Professional Journal of English Education), vol. 1, no. 2, 2019, doi: 10.22460/project.v1i2.p139-144

[8] F. Junizar and S. Sudiyono, "The Effectiveness Between Discovery Learning And Word Wall Methods In Improving Vocabulary At Seventh Grade Students," PROJECT (Professional Journal of English Education), vol. 3, no. 2, 2020, doi: 10.22460/project.v3i2.p180-186.

[9] M. Mohamed and Heba, "The Using of SAVI(Somatic ,Auditory ,Visual and Intellectual approach) in Improving Vocabulary, Listening and Creative Thinking Skills of Elementary Stage Pupils" vol. 17, no. 2, 2020, doi: 10. $21608 / j$ fe.2020.124835.

[10] R. D'Alesio, M. T. Scalia, and R. M. Zabel, "Improving Vocabulary Acquisition with Multisensory Instruction," 2007

[11] I. Ilinawati and Y. P. Dharma, "Improving Students' Vocabulary Through Songs," JEES: Journal of English Educational Study, vol. 1, no. 2, 2019, doi: 10.31932/jees.v1i2.329. 
[12] Nadhifan Dzulfahmi and A. Nikmah, The Effects of Using Movies in Improving Vocabulary and Motivation to Learn among Students across Different Age Groups, 2020.

[13] B. O. Gudu, "Teaching Speaking Skills in English Language Using Classroom Activities in Secondary School Level in Eldoret Municipality, Kenya," J. Educ. Pract., vol. 6, no. 35, pp. 55-63, 2015.

[14] P. L. Griffith and J. Ruan, "Story Innovation: An Instructional Strategy for Developing Vocabulary and Fluency," The Reading Teacher, vol. 61, no. 4, 2007, doi: 10.1598/rt.61.4.6.

[15] M. \& S. W. Bawawa, "Improving Students' Vocabulary Comprehension In Learning English Through PIcture," Musamus Journal of Language and Literature, vol. 2, no. 2, 2020.

[16] S. Yanti, "Improving Students' Vocabulary Mastery Through Electronic Dictionary," Indonesian EFL Journal, vol. 2, no. 2, 2017, doi: 10.25134/ieflj.v2i2.641.

[17] R. Ahmmed, "Effectiveness of Reading English Newspapers for Improving Vocabulary and Reading Skills of Students of Dhaka University," The Millennium University Journal, vol. 1, no. 1, 2016.

[18] S. Lei, A. Berger, B. Allen, C. Plummer, and W. Rosenberg, "Strategies for Improving Reading Skills among ELL College Students," Reading Improvement, vol. 47, no. 2, 2010 